\title{
Computer Evaluation of Acid-Base Disorders
}

\author{
Howard L. Bleich \\ From the Department of Medicine, Harvard Medical School at the Beth Israel \\ Hospital, Boston, Massachusetts 02215
}

\begin{abstract}
A B S T R A C T With the advent of electronic computers that operate in the time-sharing mode, it has become possible to develop an automated system that can assist a physician in solving clinical problems. In the present study a teletype terminal has been linked to a timesharing computer which has been programmed to evaluate clinical and laboratory information concerning patients with acid-base disorders. The program checks the data for evidence of internal consistency and requests additional information as needed to solve the acid-base aspects of the clinical problem. If sufficient information is provided, the program generates an evaluation note designed to review with the physician the pathophysiology of the disorder and to assist him in its management. If the input data are incomplete, the program draws the most useful conclusions possible based on the data provided, specifies the limitations which pertain to these conclusions, suggests further studies designed to circumvent these limitations, and while awaiting the results, suggests appropriate interim therapeutic measures. The time required to enter a patient's data and to print the evaluation note is approximately $4 \mathrm{~min}$; the cost is comparable to that of many laboratory tests.
\end{abstract}

\section{INTRODUCTION}

Despite the proliferation of medical knowledge during the past $20 \mathrm{yr}$, the methods by which knowledge is communicated to the practicing physician have remained virtually unchanged. It is true that in some areas a local telephone call now yields a 5 min recorded discussion of almost any medical topic (1), and that computers have been programmed to help read electrocardiograms (2, 3 ), to take medical histories (4), to enter data from the physical examination (5), and to perform statistical calculations helpful in diagnosis $(6,7)$. Important as these contributions are, however, none of them summon relevant information from current clinical teaching, integrate this information with data from a particular pa-

Received for publication 26 November 1968 and in revised form 31 March 1969. tient, and present the result to a physician in a form that can be used to influence his diagnostic and therapeutic decisions. Accordingly, it continues to devolve to the clinician to read or hear about each significant advance, to critically evaluate the data, to extract the clinical significance, and then to apply the pertinent conclusion to his patient.

In an effort to explore a new solution to this problem, current concepts concerning acid-base disorders have been translated into a time-sharing computer program that can be used to assist the physician in treating the patient. It should be emphasized that the purpose of this program is not to replace the physician, but to provide him with specific information that focuses upon the problem under consideration. In most instances the program does not make a diagnosis, but rather suggests a differential list that is designed to broaden the basis for the physician's decision.

The program begins by requesting appropriate input data, such as serum sodium concentration, blood $\mathrm{pH}$, etc., to which the physician responds with whatever information is available to him. Using relationships such as the Henderson-Hasselbalch equation, the program requests resolution of any inconsistencies in the data and, where possible, calculates values that were not supplied. It then requests whatever additional information may be needed to characterize the etiology and severity of the acid-base abnormality. Finally, by interposing derived and given data among appropriate excerpts from a bank of English text, it assembles an evaluation note designed for use either by the physician in managing the patient or by the student in learning the pathophysiology. Although the present program is limited to problems in acid-base equilibrium, in principle, other areas of medical specialization would seem to be amenable to the same technique.

\section{METHODS}

The program was written for a PDP-1D computer (Digital Equipment Corporation, Maynard, Mass.) with a rapid access memory totaling 60 million characters. Memory required by the program is less than $0.1 \%$ of this capacity. The 


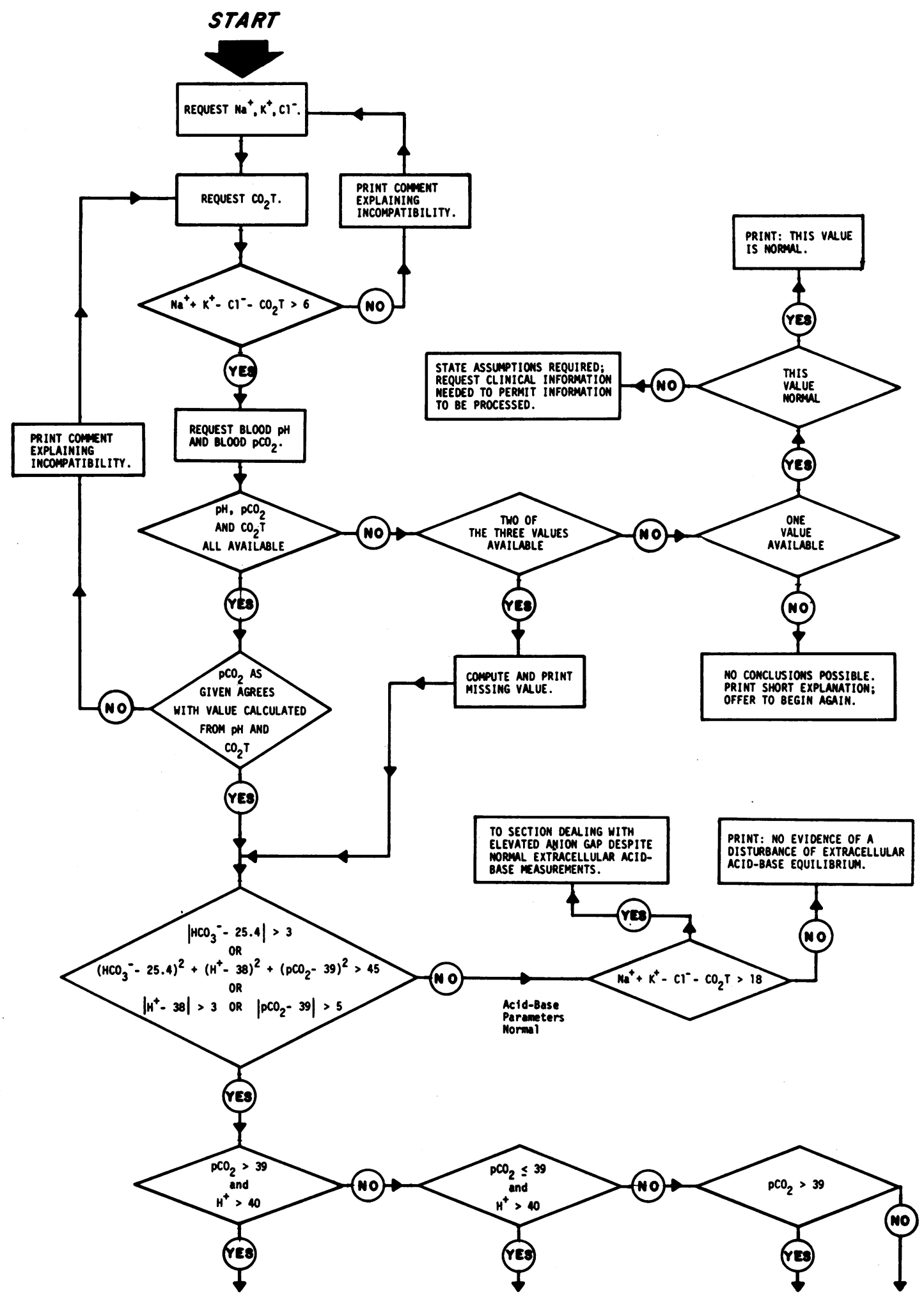

FIGURE 1 Collection of acid-base data when sodium, potassium, and chloride have been provided. Serum electrolytes are expressed as $\mathrm{mEq} /$ liter, carbon dioxide tension as $\mathrm{mm} \mathbf{H g}$, and hydrogen ion activity as $\mathrm{nEq} /$ liter. Not shown in the figure are additional pathways that check each entry to proper syntax and for compatibility with life. The terminating arrow in the lower left corner leads to the pathways shown in Fig. 2; the remaining terminating arrows lead to sections of the program not shown in the figures. 
computer is programmed for time sharing, that is, it cycles from one user to another working on each problem either until it is complete or until an allotted time interval has elapsed, at which time the unfinished portion is switched out and completed in a subsequent cycle. This technique permits the computer to serve as many as 64 remotely located tele- type terminals simultaneously and to respond to each user almost instantaneously.

The program was written in Stringcomp (8), a high-level interpretive language with provisions for string manipulation and for numerical computation. String manipulation, the property of being able to store information without regard

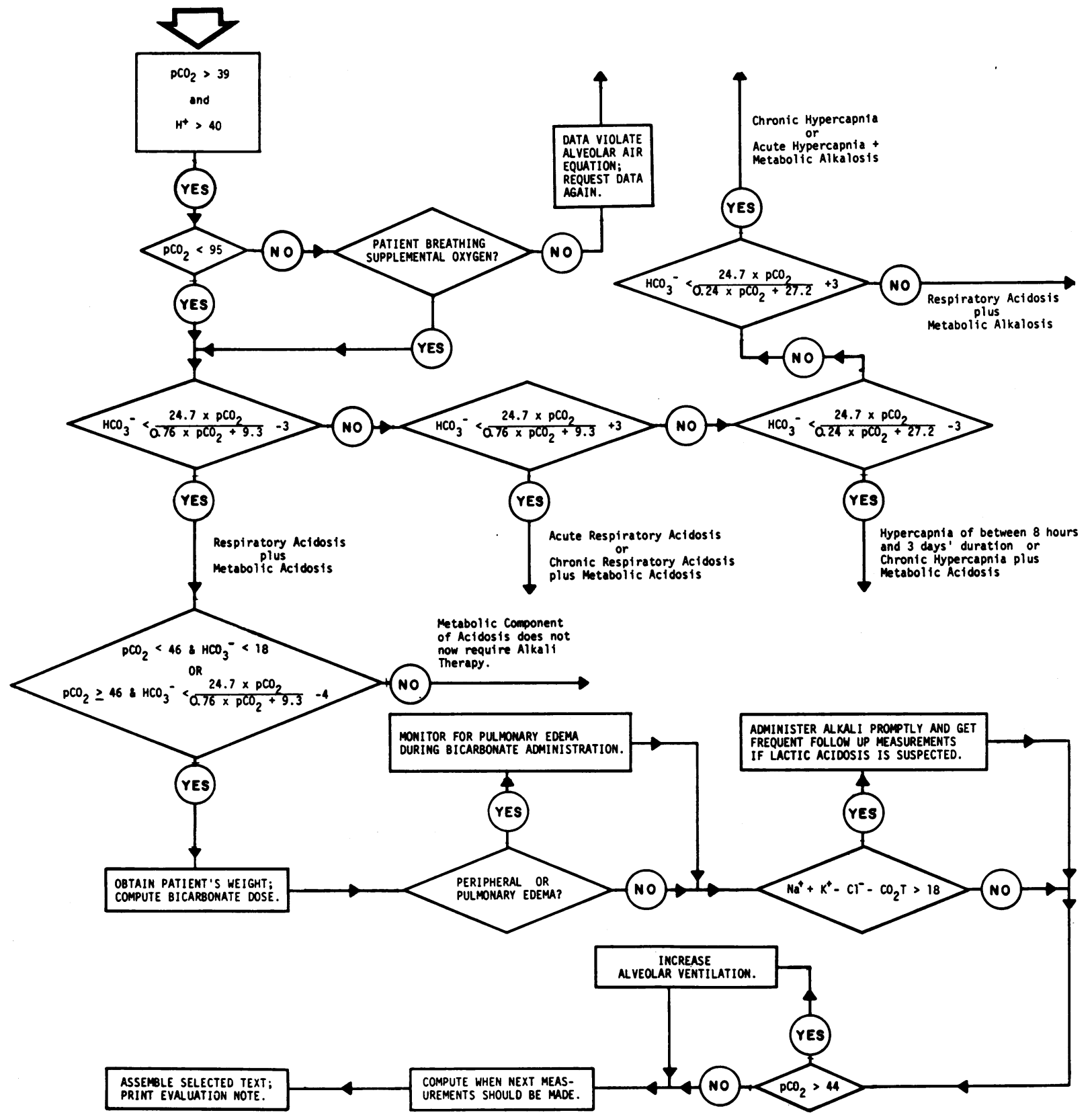

FIgURE 2 Partial diagram of some of the pathways used to characterize an acid-base disturbance. In these pathways the patient's data are compared with whole-body carbon dioxide titration curves in order to determine whether or not the values are compatible with acute or chronic hypercapnia, and whether or not a metabolic acidosis or alkalosis is superimposed. Equations for the titration curves and for the width of the confidence bands have been derived from the literature (9-10). 
to length or content and to process it on the basis of nonnumerical criteria, permits wide flexibility in communication between physician and computer. For example, it permits the physician's responses to be accepted as a string, with an illegal response summoning an explanatory comment directed by the program rather than by the programming language.
Effective processing of illegal entries renders the program auto-instructional, with even the inexperienced user being able to recover from an error and to proceed immediately.

In addition, string manipulation permits the creation of elaborate programs for inserting, deleting, and editing text and instructions. These programs, which contribute signifi-

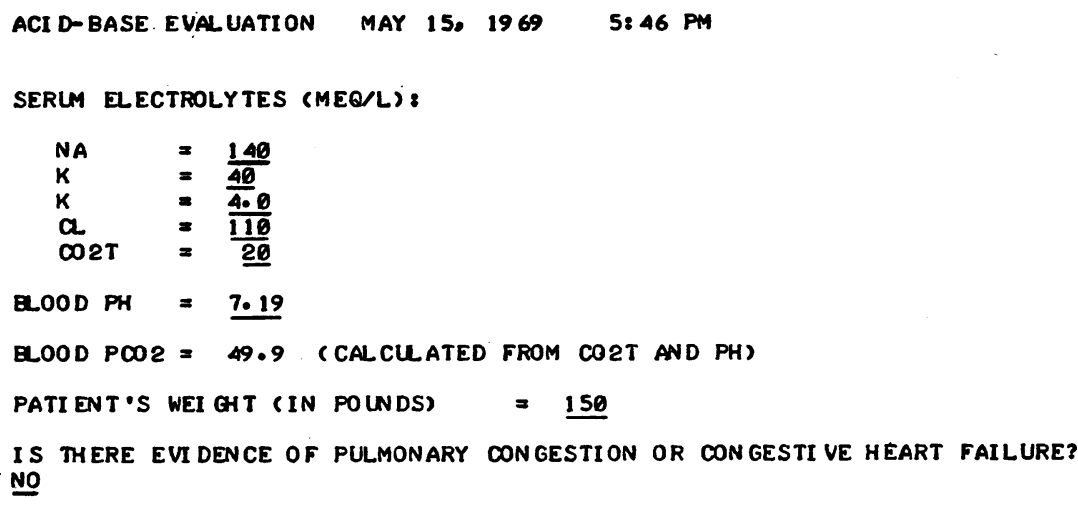

FIGURE 3 Entry of patient's data and computer-generated evaluation. Underlined information was typed by the physician, everything else by the computer. Note that the initial potassium entry was rejected as being unreasonable, and that the computer supplied the $\mathrm{pCO}_{2}$ when the physician pressed only the enter button. The bicarbonate deficit is calculated on the basis of two-thirds of total body water, but the suggested dose (usually less than the deficit) is rounded off to the nearest ampoule when the patient's weight exceeds $50 \mathrm{~kg}$. 
cantly to the speed and convenience of writing the main program, are written in the same interpretive language, and they may therefore reside in active memory while the main program is being written, modified, or run.

The program begins by collecting input data according to a logic network shown in Fig. 1. It can be seen that the program uses relationships among input variables, both to check that each new entry is consistent with previous values, and, where possible, to calculate values that were not supplied. Only the principal pathways are shown in the figure: for example, if the user provides the serum concentrations of sodium, potassium, and chloride but not the total $\mathrm{CO}_{2}$ content, the total $\mathrm{CO}_{2}$ content calculated from $\mathrm{pH}$ and $\mathrm{pCO}_{2}$ must yield an unmeasured anion concentration greater than 6 $\mathrm{mEq} /$ liter before the program can proceed.

If all requested (and calculated) laboratory data are normal, the program prints a statement to the effect that no significant disturbance of extracellular acid-base equilibrium is present. If the input data are incomplete, or if they provide evidence of a possible abnormality of acid-base equilibrium, control of the program passes to the appropriate sections for further processing.

Representative pathways comprising one of these sections are shown in Fig. 2. As before, only a portion of the possible pathways are shown, and these in only high-level form. For example, the figure considers an anion gap abnormal if it exceeds $18 \mathrm{mEq} /$ liter, whereas the program compares the magnitude of the elevation of the anion gap with the magnitude of the bicarbonate deficit in order to determine whether or not a metabolic acidosis is associated with accumulation of chloride or of an unmeasured anion. Terminating arrows lead to sections of the program not shown in the figures.

When the data indicate that an acid-base disturbance is present the program provides, where possible, a differential diagnosis of the disturbance. When further clinical information is required before the disorder can be characterized, or before treatment can be prescribed, in some instances this information is requested and processed, whereas in others the printout contains explanatory material designed to assist the physician in choosing among alternatives. In either case, the final evaluation note reflects both clinical and laboratory information currently thought to be useful in managing the acid-base aspects of the patient's problem.

\section{RESULTS}

The program may be called from any general purpose teletype terminal connected to the Bell Telephone System. When the terminal is activated and the program is called, the computer transmits acid-base evaluation, the date, the time, and then asks for serum electrolytes in $\mathrm{mEq} /$ liter (Fig. 3). After typing " $\mathrm{Na}=$ " the terminal pauses until the physician makes his response. If requested information is unavailable, the physician pushes only an "ENTER" button. Mistakes can be erased with a "RUB OUT" button; entries that violate required syntax or that are incompatible with life are requested again.

Shortly after the last entry, the program prints its evaluation note. The length of each note varies from four words to approximately two pages, depending upon the complexity of the abnormality presented. When available information is relatively complete and the problem suffi- ciently complex, the note reviews the pathophysiology of the acid-base disorder, suggests etiologic possibilities, calculates appropriate electrolyte therapy, indicates determinations that should be remeasured subsequently, and provides a short list of particularly pertinent references to the medical literature. When the input data are incomplete (Fig. 4) the program seeks to obtain information in other forms; if crucial information is simply not available, the program is designed to draw the most useful conclusions possible based on the data provided.

The program will process information concerning any combination of acidosis or alkalosis, whether respiratory or metabolic, acute or chronic, compensated or not. The data may be presented spontaneously in any order desired, or, as was shown in the examples, each piece of information may be entered when requested by the program. The present version of the program considers only the single set of values obtained at a particular time, a limitation that can be circumvented in part by the repeated entry of serial data; it is hoped that later versions will consider the temporal profile of a disorder. Sections which solve problems of sodium and potassium balance also remain to be written.

\section{DISCUSSION}

Rules of syntax can facilitate the automated manipulation of words just as rules of mathematics can facilitate the automated manipulation of numbers. In the present study syntactical properties of English, as well as current clinical teaching, have been incorporated into a computer program which accepts clinical and laboratory data concerning patients with acid-base disorders and generates in return a grammatically acceptable evaluation note.

The computer program consists of instructions and English text. The instructions direct the computer to request input data, perform numerical calculations, make logical comparisons, and select a series of subscripted symbols, each of which refers to a particular string of English text. The final instructions isolate the selected symbols, combine the corresponding text with given or derived numerical or textual information in the data base, and print the result in the form of an evaluation note.

Contained within the program instructions are algebraic expressions and Boolean comparisons required to evaluate a patient with an acid-base disorder. In those instances in which the literature (9-17) permits a complex disorder to be confidently dissected into its components, as in the example shown in Fig. 3, each component is identified and processed. As the confidence with which a particular diagnosis can be made decreases, i.e. as data from the patient approach the 
SERLM DECTROLYTES (MEO/L):

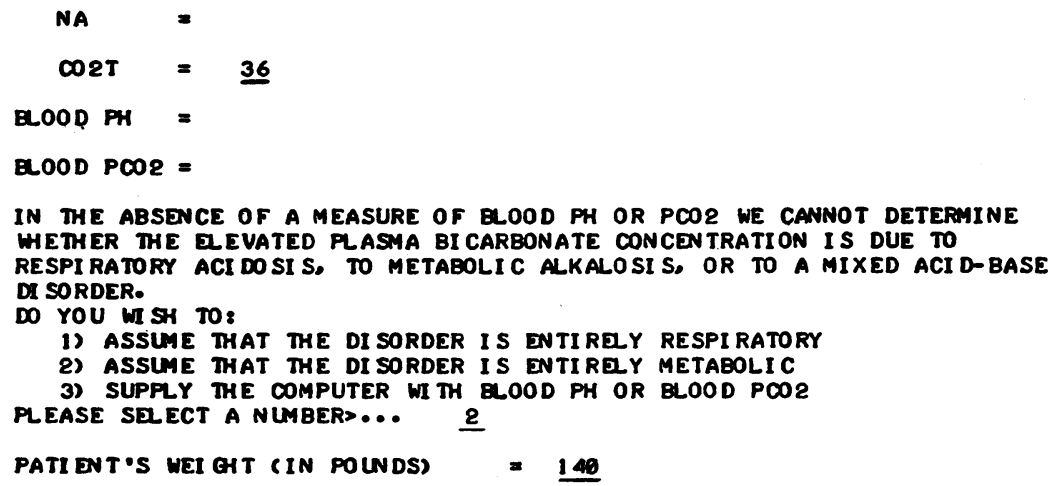

D YOU HAVE A COMPLETE SET OF SERLM ELECTROLYTES?...$\quad$ NO

IT WOLD PROBABLY BE USEFL TO OBTAIN THEM.

If WE ASSUME THAT THE ACI D-BASE DI STURBANCE IS ENTIREY METABOLIC. THE COET OF 36 MEQ/ IMPLIES THAT PH MUST BE 7. 48 UNITS AND

PCO2 46 MM HG, SINCE THESE ARE THE VALUES THAT WOLD BE COMPAT-

IBLE WI TH UNCOMPLI CATED METABOLIC ALKALOSIS.

WILE AWAI TING A COMPLETE SET OF EECTROLYTES IT SHOLD BE RECALLED THAT METABOLI C ALKALOSI S IS MOST COMMONLY CAUSED BY:

1) VOMI TING OR GASTRI C ASPIRATION

2) DI URETI C THERAPY ( THI AZI DES, MERCURI ALS, ETHACRYNIC ACI D, OR FUROSEMI DE)

3) HYPERADRENALI SM CCUSHINGS SYNDROME, PRIMARY OR SECONDARY ALDOSTERONI SM, ADRENAL STEROI D THERAPY)

4) EXCESSI VE ALKALI INTAKE (ALKALOSIS USUALLY TRANSI ENT)

5) POST HYPERCAPNI A (PARTI CLLARLY IF CHLORI DE INTAKE IS SMALL)

6) HYPERCALCEMI A ( POSSI BLE--DATA NOT CLEAR)

7) BARTTER 'S SYNDROME (HYPOKAL DMIA, HYPOCHLORDMIA, AND METABOLIC ALKALOSI S, WI TH, IN SOME INSTANCES, HYPONATREMI A, SHORT STATURE, AND MENTAL RETARDATION.)

IF HYPERADRENALI SY AND HYPERCALCEMIA ARE ABSENT, THEN IT SHOLLD BE POSSI BLE TO CORRECT THE METABOLIC ALKALOSIS BY ADMINISTERING SUFFI CI DNT CHLORI DE TO REPLACE PREVIOUS LOSSES AND TO ALLOW A URINARY CHLORI DE EXCRETION OF AT LEAST 10 TO 20 MEO PER DAY.

THE TOTAL CALCLATED CHLORI DE DEFICIT IS APPROXIMATEY 130 MEO. IT IS SUGGESTED, HO WEVER, THAT IN ADDI TION TO REPLACING KNOWN CHLORI DE LOSSES, 100 MEO OF SODI UM, POTASSI LM, OR ARGNINE CHLORI DE BE G VIN INTRAVJNOUSY DURING THE NEXT 24 HOURS, AND THAT SERLA EECTROLYTES AND BLOOD PH BE MEASURED AT LEAST DAILY UNTIL SI GNI FI CANT IMPRO VDA UT IN THE ACI D-BASE ABNORMALI TY OCCURS.

THANK YOU FOR REFERRING THIS INTERESTING PATI ENT TO US.

REFERJNCES?

1) COLDRING R.M., CANNON, P.J., HEINUMANN, H.0., AND FI SHMAN, A.P. RESPI RATORY ADJUSTMENT TO CHRONIC METABOLIC ALKALOSIS IN MAN J. CIIN. INVEST., $47 ; 188,1968$.

2) BEESON, P.B. AND MCDERMOTT, Wo CECIL-LOEB TEXTBOOK OF MEDI CINE 12 TH EDI TION (1967), P. 763 .

3) KASSI RER, J.P., BERKMAN, P.M., LAWRENZ, D.R., AND SCHWARTZ, W० B. THE CRI TI CAL ROLE OF CHLORI DE IN THE CORRECTION OF HYPOKALEMIC ALKALOSIS IN MAN.

AMER. J. MED., 38, $172,1965$.

<*>

FIGURE 4 Computer-generated evaluation-minimal data supplied. The program is designed to request required information in alternative ways, but it will process whatever information is provided. In this example the chloride deficit has been taken to be equal to the bicarbonate surplus calculated on the basis of two-thirds of total body water. 
border zones, appropriate qualifying modifiers such as "probably," and "relatively," etc., are inserted into the output text.

When the results of needed experiments are not available, as in the case of renal compensation for chronic respiratory alkalosis, equations to describe the phenomena were necessarily assumed. Indeed, the program contains innumerable assumptions and value judgments, many of which are open to difference of opinion. In future versions evaluation notes could be made to reflect divergent views and to indicate the assumptions which underlie each. It is thus apparent that the formulation and continual updating of the instructions and text which constitute the program require that the basis for each clinical decision be precisely defined. They require that the investigator clearly distinguish what is known from what is assumed, and that each decision based on an assumption be reexamined as soon as the reason for that decision can be replaced by the results of new clinical research. To specify precisely the rationale for each clinical judgment is, in itself, a useful exercise, particularly if it unmasks areas where additional clinical research is needed or where current teaching is inconsistent or illogical.

Since the computer printout includes diagnostic conclusions and therapeutic suggestions together with the rationale for each, it can serve as a continual source of instruction for both medical students and practitioners. In our experience most users study the printout from a particular patient and then experiment with assumed data concerning related disorders until satisfied that they can predict the output. Since the computer performs the arithmetic, the user can concentrate on the pathophysiology. Rather than tempting the clinician to rely passively upon the computer, use of the program appears to encourage him to think about broad areas of acid-base physiology.

In addition to teaching the pathophysiology of acidbase disorders, use of the program tends to inculcate principles of data evaluation that are more widely applicable. For example, as soon as a user enters a datum which is inconsistent with any previous entry, the program prints an explanatory comment that describes the nature of the incompatibility and asks for retraction of any one entry which will restore internal consistency. After being corrected once or twice in this manner, the user tends to sharpen his own discipline for performing internal checks on clinical data. In addition, the increased likelihood that data will be checked, either by computer or by clinician, should significantly improve quality control in the laboratory. How long the dis- cipline persists and whether or not it will improve the handling of other clinical data have not been determined.

Since the program was written for a time-sharing computer connected to the Bell Telephone System, any physician with access to a general-purpose teletype terminal can call the program and enter data. Efficient use of the program requires neither typing skill nor special training; only a few characters at a time are entered by the user, and each entry is adequately explained by the program. A six-letter confidential code protects the program from unauthorized modification or deletion. In addition, each night the entire computer memory is copied onto magnetic tape and stored remotely; in the event of damage to the memory, the entire system can be reloaded from the previous tape. Except for the time required to copy the memory, for other routine maintenance, and for occasional equipment failures, the system is in operation at all times.

If a computer program is to be widely available (even at times of equipment maintenance and failure), it must run on a variety of equipment. In an effort to assess the difficulty of replication, the program was translated into BASIC for a GE-635 computer which serves a wide area in New England from the Kiewit Computation Center at Dartmouth College. Except for minor differences in format, the two versions appear identical to the user. To translate the program into BASIC required less than two months, ${ }^{1}$ but it should not be assumed that the program can be translated into a form suitable for any time-sharing installation in a similar interval; ease of translation is a function of the properties of the available programming language."

The cost for computer time at both installations is approximately fifty cents per note, to which must be added the proportionate cost of renting (approximately $\$ 75$ / month) or purchasing (approximately $\$ 570$ plus servicing) the teletype unit, and the cost of telephone transmission. Accordingly, it would appear that as soon as terminal and transmission costs can be shared among several medically useful programs, such a system could contribute significantly to medical teaching and practice.

\section{ACKNOWLEDGMENTS}

This work was supported in part by the General Research Support Grant to the Beth Israel Hospital, and by grants from the Milton Fund, Harvard Medical School and the John A. Hartford Foundation, New York.

\footnotetext{
${ }^{1}$ The program was translated by Mr. William Campbell under the supervision of Dr. George Stibitz and Dr. Howard Green.

A copy of the program, either in STRcomp or in BASIC, may be obtained from the author. A user's manual describing the STRcomp language may be obtained from Bolt, Beranek and Newman, Inc., Cambridge, Mass.
}

Computer Evaluation of Acid-Base Disorders

1695 


\section{REFERENCES}

1. Meyer, T. C. 1968. Medical dial-access tape library-an experiment worth continuing. Abstracts of Annual Conference on Research in Medical Education, Association of American Medical Colleges. November 1-2. 12.

2. Pipberger, H. V., E. D. Freis, L. Taback, and H. L. Mason. 1960. Preparation of electrocardiographic data for analysis by digital electronic computer. Circulation. 21: 413.

3. Caceres, C. A., C. A. Steinberg, P. A. Gorman, J. B. Calatayud, R. J. Dobrow, and A. L. Weihrer. 1964. Computer aids in electrocardiography. Ann. N. Y. Acad. Sci. 118: 85.

4. Slack, W. V., G. P. Hicks, C. E. Reed, and L. J. Van Cura. 1966. A computer-based medical-history system. N. Engl. J. Med. $274: 194$.

5. Slack, W. V., B. M. Peckham, L. J. Van Cura, and W. F. Carr. 1967. A computer-based physical examination system. J. Amer. Med. Ass. 200: 224.

6. Warner, H. R., A. F. Toronto, L. G. Veasey, and R. Stephenson. 1961. A mathematical approach to medical diagnosis. J. Amer. Med. Ass. 177: 177.

7. Gorry, G. A., and G. O. Barnett. 1968. Sequential diagnosis by computer. J. Amer. Med. Ass. 205: 849.

8. Dominick, V. M. 1968. STRcomp and ISRcomp: A User's Manual. Medical Information Technology Department, Bolt, Beranek and Newman, Inc., Cambridge, Mass.
9. Brackett, N. C., Jr., J. J. Cohen, and W. B. Schwartz. 1965. Carbon dioxide titration curve of normal man. N. Engl. J. Med. $272: 6$.

10. Brackett, N. C., Jr., C. F. Wingo, O. Muren, and J. T. Solano. 1969. Acid-base response to chronic hypercapnia in man. N. Engl. J. Med, 280: 124.

11. Sapir, D. G., D. Z. Levine, and W. B. Schwartz. 1967. The effects of chronic hypoxemia on electrolyte and acidbase equilibrium: an examination of normocapneic hypoxemia and of the influence of hypoxemia on the adaptation to chronic hypercapnia. J. Clin. Invest. 46: 369.

12. Beeson, P. B., and W. McDermott. 1967. Cecil-Loeb Textbook of Medicine. 12th edition, W. B. Saunders Company, Philadelphia. 763.

13. Goldring, R. M., P. J. Cannon, H. O. Heinemann, and A. P. Fishman. 1968. Respiratory adjustment to chronic metabolic alkalosis in man. J. Clin. Invest. 47: 188.

14. Kassirer, J. P., P. M. Berkman, D. R. Lawrenz, and W. B. Schwartz. 1965. The critical role of chloride in the correction of hypokalemic alkalosis in man. Amer. J. Med. 38: 172.

15. Lennon, E. J., and J. Lemann, Jr. 1966. Defense of hydrogen ion concentration in chronic metabolic acidosis. Ann. Intern. Med. $65: 265$.

16. Stinebaugh, B. J., and W. H. Austin. 1967. Acid-base balance. Common sense approach. Arch. Intern. Med. 119: 182.

17. Winters, R. W., J. A. Lowder, and N. K. Ordway. 1958. Observations on carbon dioxide tension during recovery from metabolic acidosis. J. Clin. Invest. 37: 640. 